\title{
Álvaro Santana Acuña, Ascent to Glory. How One Hundred Years of Solitude Was Written and Became a Global Classic. Nueva York, Columbia University Press, 2020, 370 páginas
}

\section{Paula Salinardi}

Cita sugerida: Salinardi, P. (2021). [Revisión del libro Ascent to Glory. How One Hundred Years of Solitude Was Written and Became a Global Classic por P. Salinardi]. Orbis Tertius, 26(33), e206. https://doi.org/10.24215/18517811e206

Que el boom latinoamericano es un núcleo temático que todavía hoy merece la atención de críticos y docentes de todo el mundo no es novedad. Desde una perspectiva político-cultural, puede servir para pensar los años sesenta, década que aún suscita revisiones y polémicas. Desde los estudios sobre el libro y la edición, el boom latinoamericano representa un caso paradigmático para pensar cómo se dan las relaciones entre autores, editores, críticos y cómo se tejen las redes intelectuales para que ciertos textos se den a conocer. Durante este proceso, una parte de la narrativa latinoamericana encontró un reconocimiento tanto de crítica como de ventas en nuestro continente y en los países centrales, en especial europeos. Tiene lugar entonces una potente internacionalización de autores y textos latinoamericanos. Durante este período autores como Gabriel García Márquez, Mario Vargas Llosa, Carlos Fuentes, Julio Cortázar, entre otros, lograron traspasar los distintos escenarios nacionales; en términos de mercado editorial, el fenómeno afectó de manera notable la edición y la circulación de la narrativa latinoamericana.

El libro de Álvaro Santana Acuña, actualmente profesor del Whitman College de Washington, fue publicado en 2020 y presenta un estudio pormenorizado sobre uno de los textos más emblemáticos del boomlatinoamericano, Cien años de soledad de Gabriel García Márquez, el que, sin duda, constituye uno de los momentos paradigmáticos de este proceso. Como señala en la Introducción, la novela del colombiano fue traducida a cuarenta y nueve idiomas y vendió cerca de cincuenta millones de copias en todo el mundo, además de ser uno de los libros más vendidos de todos los tiempos; esto hizo que se transformara en uno de los textos en español más leídos después de El ingenioso hidalgo Don Quijote de la Mancha. 
Santana Acuña afirma que escribió este libro para fanáticos de Cien años de soledad y para estudiosos de distintas áreas (sociología, historia, literatura). Su objetivo era presentar un estudio sobre la concepción de la novela, su éxito y transformación en best seller, y su consagración cómo clásico. Para quienes lleguen al libro sin demasiados conocimientos previos, puede resultar muy interesante ya que aporta numerosos datos mediante un tono ameno y claro.

El libro está dividido en dos grandes partes: la primera parte, llamada "From the Idea to the Book", trabaja con el período comprendido entre 1920 y 1967 , año de la publicación de la novela. La segunda parte, llamada "Becoming a Global Classic", se centra en el período comprendido entre 1967 y 2020. Además, hay un apéndice: "Why and How to Study Classics?".

La primera parte está compuesta por cuatro capítulos: "Imagining a work of art", "The Publishing Industry Modernizes", "A Novel in Search of an Author" y "Networked Creativity and the Making of a Work of Art". Esta división le permite a Santana Acuña, por un lado, reconstruir cuál fue el escenario en el que se insertó el libro, es decir, cuáles fueron las particularidades del campo intelectual de la época que permitieron que el libro pudiera, en cierto sentido, escribirse. Por otra parte, echa luz sobre cuál fue el proceso de García Márquez para encontrar y afianzar su propio estilo. Además, analiza cuáles fueron las relaciones que García Márquez trabó con sus pares y con otros actores que resultaron una pieza clave para que el libro se publicara: su agente, Carmen Balcells, y las editoriales que publicaron sus textos.

A partir de la reconstrucción del campo cultural durante las décadas previas a la publicación de la novela (1920-1967) y de la vida de Gabriel García Márquez, se analizan ideas, estilos, actores y organizaciones que permitieron que Cien años de soledad pudiera imaginarse como una obra de arte. En este sentido, subraya la idea de que esta novela fue un trabajo colectivo del que participaron amigos, colegas, editores y hasta la mecanógrafa; colaboraron investigando, proponiendo lecturas, leyendo fragmentos, publicando algún avance editorial.

La idea de cosmopolitismo es importante para el autor ya que da cuenta del proceso que llevan adelante muchos de los autores que escriben y publican durante este período. Por una parte, la transformación de la industria editorial en español que permitió el crecimiento de las editoriales en América Latina, pero también que muchos autores latinoamericanos llegaran a ser publicados en editoriales que rompían las barreras nacionales; en consecuencia, hay un notable aumento en la circulación de autores latinoamericanos. En segundo lugar, advierte sobre la aparición de un nuevo modo de decir y de pensar lo latinoamericano, que se acerca más a lo universal y se aleja de lo local y folclórico. A partir de las correcciones en el manuscrito de Cien años de soledad puede verse cómo algunas modificaciones apuntan a universalizar y desmarcar a Macondo, y a evitar las referencias que pudieran ubicarlo en Colombia: Macondo está en cualquier parte.

La segunda parte, que aborda los años 1967 a 2020, está compuesta también por cuatro capítulos: "Controversy, Conflict, Collapse”, "A Novel without Borders", "Indexing Classics” y "Ascent to Glory for Few, Descent to Oblivion for Most”. A lo largo de estas páginas, Santana Acuña explica cómo ocurrió el ascenso a la gloria que da título a su libro. Se retoman las polémicas que se suscitaron - y se siguen suscitando - en torno al boom latinoamericano y los argumentos con que los autores que formaron parte de este proceso respondieron a esas críticas. El derrumbe del nicho, como lo llama el autor, que permitió que Cien años de soledad fuera imaginada y producida y que facilitó su circulación, posibilitó, paradójicamente, que en cierta medida el texto se transformara en un clásico. Después de ese primer momento en que funcionaba el nicho de la Nueva Novela Latinoamericana, García Márquez, y otros autores del boom, se dedicaron a continuar sus carreras en solitario y ya no como parte de una unidad.

A través del análisis de datos de varios países, el libro da cuenta de cómo distintos cultural brokers (agentes o mediadores culturales) facilitaron la circulación de la novela a lo largo del mundo y a través de varias generaciones a partir de los años setenta. La idea con la que trabaja Santana Acuña es que los mediadores culturales no son solo los críticos y estudiosos que escribieron y trabajaron sobre Cien años de soledad, sino personas, organizaciones, grupos no vinculados entre sí que desde acciones individuales obtuvieron un 
resultado colectivo: crearon un campo que pudiera recibir una obra como la del colombiano y consagrarla de la manera en que fue consagrada. Estos mediadores culturales son tanto o más importantes en la consagración del libro como los gatekeepers, es decir, los agentes y editores que lo convirtieron en un clásico. Asimismo, señala algunos de los aspectos del texto o que lo rodean (la frase inicial, Macondo, el ascenso al cielo de Remedios, entre otros) que son considerados significativos y representativos, y que se transformaron en marcadores reconocibles universalmente para los mediadores culturales, y sirvieron, entre otras cosas, para transformar la novela en un clásico global.

En el Apéndice titulado "Why and How to Study Classics?", se retoma la idea que da vida al libro, la de reconstruir cómo un libro se hace y no solamente pensar en que es el trabajo de un genio o de los mediadores culturales que ayudan a que el libro circule. En el caso de Gabriel García Márquez, Santana Acuña señala que se trata de un genio hipersocializado, es decir, un escritor que conocía y dominaba las reglas del juego social, y que, a partir del intercambio con sus pares pudo escribir este texto que lo catapultó a la fama. Al llenar el vacío y reconstruir cómo Cien años de soledad - y derribando algunos mitos en torno a su génesis- fue escrito, el autor se mete en el debate sobre cuáles fueron las razones que hicieron que un texto se transformara en un clásico que trascendió fronteras y que todavía hoy, y a pesar del tiempo transcurrido, sigue mereciendo nuestra atención. 